\title{
FORMAÇÃO DOCENTE E INTERDISCIPLINARIDADE EM TEMPOS DE PANDEMIA COVID-19
}

\author{
TEACHER TRAINING AND INTERDISCIPLINARITY IN TIMES OF PANDEMIC COVID-19
}

Solange Martins Oliveira Magalhães

Doutora em Educação

Professora Titular - Programa de Pós-Graduação em Educação.

Universidade Federal de Goiás - UFG. Goiânia, GO - Brasil solufg@hotmail.com

(iD) Simei Araújo Silva

Doutora em Educação

Professora do curso de Pedagogia. Universidade Federal de Goiás Goiânia, GO - Brasil simeiaraujo@hotmail.com

Leandro Silva de Paula Doutor em Educação e em Historiador. Professor do curso de Pedagogia. Universidade Federal de Goiás Goiânia, GO - Brasil leandroufg204@gmail.com

\begin{abstract}
Resumo: O atual cenário de Pandemia de Covid-19 exigiu reorganizações imediatas do trabalho docente para adaptá-lo ao ensino remoto emergencial. Na especificidade da docência, na universidade pública, surgem novas formas de trabalho com ferramentas digitais e tecn ológicas, o que exigiu a revisão de princípios fundantes da docência associada a formação integral - bildung. O ensino remoto altera a essência da docência, exigindo novas formas de atuação que ajudem a superar a fragmentação que o ensino remoto tem imposto à docência e a formação de professores na universidade pública. Neste artigo apresentamos um relato de experiência fundamentada na interdisciplinaridade. Embora tenhamos identificado sua aprovação, uma parcela dos estudantes relatou fadigas em relação ao tempo de exposição à tela do computador, além de dificuldades em participar dos debates, e assimilar o conteúdo neste novo fo rmato de ensino.
\end{abstract}

Palavras chave: docência; educação; educação pública; pandemia do Covid-19.

Abstract: The current Pandid-19 Pandemic scenario called for immediate reorganizations of teaching work to adapt it to emergency remote education. In the specificity of teaching, in the public university, new ways of working with digital and technological tools emerge, which required a revision of the fundamental principles of teaching associated with integral training - bildung. Remote teaching alters the essence of teaching, requiring new forms of action that help to overcome the fragmentation that remote teaching has imposed on teaching and the training of teachers at the public university. In this article we present an account of experience based on interdisciplinarity. Although we identified its approval, a portion of the students reported fatigue in relation to the time of exposure to the computer screen, in addition to difficulties in participating in the debates, and assimilating the content in this new teaching format.

Key-words: teaching; education; public educacion; pandemic Covid-19.

Cite como

(ABNT NBR 6023:2018)

MAGALHÃES, Solange Martins Oliveira; SILVA, Simei Araújo; PAULA Leandro Silva de. Formação docente e interdisciplinaridade em tempos de pandemia Covid-19. Dialogia, São Paulo, n. 38, p. 1-15, e18912, maio/ago. 2021. Disponível em: https://doi.org/10.5585/38.2021.18912.

\section{American Psychological Association (APA)}

Magalhães, S. M. O., Silva, S.A., \& Paula, L. S. de. (2021, maio/ago.). Formação docente e interdisciplinaridade em tempos de pandemia Covid-19. Dialogia, São Paulo, 38, p. 1-15, e18912. https://doi.org/10.5585/38.2021.18912. 


\section{Introdução}

\section{Formação docente no período de pandemia Covid-19}

O estado de quarentena decretado em função da pandemia do Covid-19 instaurou um período de insegurança e desestabilidade, impondo ao mundo uma situação desconhecida e assustadora. Fomos colocados em distanciamento social, como tentativa de evitar colocar em situação de risco e vulnerabilidade todas as pessoas, conscientizando-as sobre os perigos da contaminação. No Brasil, o isolamento social foi estabelecido Pela Portaria No 356, de 11 de março de 2020, sustentado pela "Declaração de Emergência em Saúde Pública de Importância Internacional", pela Organização Mundial da Saúde, em 30 de janeiro de 2020, em decorrência da Infecção Humana pelo novo coronavírus (Covid-19). Ação que se estendeu à educação, a qual foi suspensa, nos níveis inicial, primário, secundário e superior, pelo Ministério da Educação/Brasil, em todo território nacional.

As medidas incidiram diretamente sobre as universidades públicas, e o trabalho que desenvolvem na formação docente, pois nesta situação excepcional, recomendou-se a adaptação de toda atividade acadêmica presencial, ao ensino remoto emergencial. Para atender as recomendações foi necessário a readaptação imediata do calendário acadêmico, sustentada como solução inevitável para a continuidade do ano letivo.

Ainda que as instituições federais tenham empreendido esforços no replanejamento das atividades docentes, as mudanças exigiram rápido ajuste e, conforme relatado por Araujo (2020, p. 2), demandou trabalho persistente dos professores com foco nas alterações solicitadas, como a exigência de uma "educação mediada por tecnologias digitais no ambiente universitário" sustentando a implantação de salas de aula virtuais como opção às aulas presenciais.

O reconhecimento, legitimação e institucionalização do ensino remoto emergencial foi aprovado a partir de intensos (e tensos) debates em cada instituição pública de ensino superior. No âmbito da Universidade Federal de Goiás (UFG) houve deliberações do Conselho Universitário $\left(\right.$ CONSUNI $^{1}$ ) por meio da Resolução CONSUNI n. 33/2020 que franquiou as regras do Regulamento Geral dos Cursos de Graduação - RGCG, aprovado pela Resolução CEPEC N ${ }^{\circ}$ 1557, de 1\%/12/2017, enquanto durar a situação de pandemia do Novo Coronavírus e até nova deliberação. As normativas, quer seja no âmbito do Ministério da Educação/Brasil ou na especificidade de cada universidade pública,

\footnotetext{
${ }^{1}$ Instruções Normativas | PROGRAD - Pró-Reitoria de Graduação da Universidade Federal de Goiás. Disponível em: https://prograd.ufg.br/p/29810-instrucoes-normativas Acesso em 01/07/2021.
} 
[...] desempenharam um papel fundamental neste contexto de excepcionalidade, pois criaram salas de aula virtuais para espaços curriculares de forma a [...] continuidade à formação na graduação e pós-graduação e nas instâncias oferecidas formação por meio de webinars ou cursos que visem a formação pedagógica e tecnológica capaz de sustentar a adaptação de propostas didáticas a ambientes virtuais de ensino e aprendizagem. (ARAUJO, 2020, p. 2).

Mesmo que as normativas tenham sido atendidas, conforme Araujo (2020), acabaram desencadeando várias tensões no coletivo de professores das universidades públicas. A implantação do Ensino Remoto Emergencial acabou garantindo a continuidade pedagógica e o percurso acadêmico, embora nem sempre em condições de igualdade de oportunidades e desempenho, pois vários docentes se defrontaram, por exemplo, com dificuldades relativas ao uso de recursos tecnológicos para desenvolver o ensino remoto, a questão da conectividade, da flexibilização dos horários, da redefinição de novas metodologias de ensino, da necessidade de trabalho coletivo, e de uma nova sistematização de processos avaliativos.

No caso da Faculdade de Educação/Universidade Federal de Goiás, o seu Conselho Diretor tem mantido a discussão sobre o lugar, o papel e a função da educação remota no contexto da formação docente que esta instituição sustenta. Nos debates questiona-se a concepção de educação é assumida, questionando-se sobre o quê, para quê e como se delibera esse novo ensinar? Sobre o como integrar a relação teoria e prática no ensino remoto emergencial? entre outras questões (ARAUJO, 2020; MAGALHÃES e MOURA, 2020; MAGALHÃES, 2020).

Nesse sentido, apresenta-se como o foco deste artigo, a reflexão sobre a docência universitária, na proposição do ensino remoto emergencial, pois ele não tem sido associado a percepção das assimetrias socioeconômicas e emocionais que se sobrepõem no processo formativo e, no caso dos estudantes do curso de Pedagogia, essas se destacam e certamente comprometem o processo do educar democrático e significativo, para uma grande parte dos nossos estudantes.

Do lugar de docentes que atuam na formação de professores, propusemos um trabalho coletivo - interdisciplinar e interativo, desenvolvido com alunos do primeiro período, turnos matutino e vespertino, do curso de Pedagogia, levando em consideração a realidade social e cultural dos professores e dos acadêmicos envolvidos no processo ensino-aprendizagem do ERE. Nesses termos, teoricamente sustentamos nosso propósito de ensino nos princípios da interdisciplinaridade, justamente por acreditar que ela possa ajudar nos afastar de uma docência fragmentada no ensino remoto, sobretudo por deliberar a aula como "ato de troca, de reciprocidade entre as disciplinas ou ciências - ou melhor, de áreas do conhecimento" (FAZENDA, 2011b, p. 34). 
Chegamos ao ponto onde destacou-se a necessidade de relacionamos interdisciplinaridade e docência universitária, relação que deixa de levar em conta apenas os conteúdos específicos de cada disciplina, pois enfatiza-se que seria na interlocução dos conteúdos disciplinares, portanto, a partir de uma ação coletiva e colaborativa, que se manifestam aspectos das subjetividades, que podem legitimar a ação docente no ensino remoto. Deste modo, essa associação interdisciplinaridade e docência, objetivou trazer para o ensino remoto, um fazer social, coletivo, dialogado, que se expressa essencialmente como "processo que precisa ser vivido e exercido", por todos os envolvidos no processo (FAZENDA, 2001b, p. 11). Ainda se faz necessário afirmar que essa associação ainda se relaciona a atitude das pessoas frente ao conhecimento e, gradativamente, alteram-se também saberes, ações e, dessa maneira, o processo formativo torna-se mais humanizador (FAZENDA, 1998; 2008; 2013; 2011a; 2011b).

Assim entendendo, a interdisciplinaridade cresce em importância no ensino remoto, enfrentando as novas maneiras de se pensar e lidar com o conhecimento no ensino remoto. No caso da formação docente fortalece o papel de cada disciplina envolvida, envolve a compreensão de suas histórias, do lugar que ocupa no currículo do curso e, impreterivelmente, na vida dos futuros professores, extrapolando, portanto, o âmbito da sala de aula. (FAZENDA, 1998; 2008; 2013; 2011a; 2011b).

No que se refere a definição de docência universitária, de modo geral, assumimos que tem um importante viés social, cognitivo e afetivo que acaba intervindo diretamente na vida dos estudantes (MAGALHÃES e MOURA, 2020; MAGALHÃES et al, 2020). Pela mediação pedagógica que promove, participa do processo de aquisição da consciência, como defendeu Vigotski (1999), a qual se constrói como possibilidade dinâmica de aprendizagem. O aporte teórico de Vygotsky, portanto, ressignifica a importância e a centralidade da docência, para a aquisição de funções psicológicas superiores - percepção atenção, memória, capacidade para solucionar problemas, e da consciência, realocando o papel das mediações, no processo de desenvolvimento do sujeito social.

Nos termos de Vigotsky (1999, p. 74), o processo de aprendizagem é fundamental como mediação, tendo lugar efetivo na conversão do indivíduo à sujeito social. Isso significa que o sujeito é histórico, e se apoia na internalização de mediadores simbólicos e culturais no desenvolvimento da consciência de si e do mundo, como afirmado na teoria de Vygotsky (MAGALHÃES; MOURA, 2020). Essa ideia encontra sustentação no pensamento marxista, Marx e Engels (2002) acreditavam que o sujeito não é apenas produto de seu meio, ele é produto e produtor do mesmo, sendo ativo nas articulações estabelecidas entre as condições materiais de sua existência e, a partir das relações 
produtivas (trabalho humano) nas quais se insere, o que também influencia na formação de sua própria consciência. Nesse sentido, numa perspectiva de compreensão da realidade como contraditória e ideológica, analisamos a execução de experiência interdisciplinar e interativa que problematiza a: 1) docência universitária na formação de professores - pressupostos teóricos; 2) docência universitária pública no contexto do ensino remoto emergencial; 3) aula interdisciplinar como proposta de trabalho coletivo, a partir da ótica de estudantes. Ao final, apresentamos algumas considerações a partir da interlocução entre docência e interdisciplinaridade, sua importância no campo da formação e professores durante o ensino remoto.

\section{A docência universitária pública e a formação docente}

Durante a pandemia do Covid-19 paira a tensão sobre a docência no processo de formação de professores. Gradativamente, destacam-se as dificuldades na utilização de estratégias pedagógicas, sobretudo no domínio de ferramentas digitais e tecnológicas, compreensão do ensino híbrido e das metodologias ativas, novas técnicas de aulas, plataformas digitais, conhecimento dos ambientes "AVA", salas de aula Google, plataforma Moodle, atividades síncronas e assíncronas, em espaços de workshops; Google Meets; Seminários via on-line, deflagando vários desafios à docência universitária, como descreveram Magalhães e Moura (2020).

Por ser muito diferente das aulas que se desenvolviam num espaço presencial, os professores buscam avançar e problematizar as bases teóricas que sustentam a sua nova forma de atuação e sobre quais são seus princípios educativos. Nesse sentido, durante os debates que são constantemente enfrentados, destacam-se as inquestionáveis exigências governamentais, frente à pandemia Covid-19, e a forma como o ensino remoto afeta a essência da formação de professores na universidade pública. Epistemologicamente, ele expressa um processo transmissional de conteúdo, a partir de uma abordagem instrucional, que pretende ter alcance em massa, via ambiente on-line. E embora seja assumido nas suas deliberações como aberto, interativo e comunicativo, como já afirmamos, infelizmente, não favorece a mediação pedagógica de forma ativa, nos termos aqui defendido, ou seja, como enfatizou Vigotski (1999).

No mês de novembro de 2020, o curso de formação de professores da Universidade Federal de Goiás completou quatro meses de docência no ensino remoto emergencial, tempo suficiente para que o Núcleo Docente Estruturante (NDE) do curso levante questionamentos sobre a realidade enfrentada. A partir das reuniões de áreas do curso, os professores dialogam constantemente sobre aspectos que estão envolvidos e o como percebem a docência frente à adaptação imediata ao ensino remoto (ERE). $\mathrm{Na}$ especificidade da área de fundamentos, os 
professores relatam que o estado de emergência alterou não só a rotina presencial, mas, como também analisado por Regueiro et al. (2020), o lócus de trabalho em extrema velocidade. Como tem sido destacado por vários autores, os professores se questionam sobre o como reconstruí-lo on-line, ao mesmo tempo em que enfrentam seus desafios, como: 1) aspectos pessoais e subjetivos: a necessidade de capacitação para o uso de ferramentas digitais, o enfrentamento de adoecimentos, mortes, internações; 2) aspecto sócio político: capacidade de lidar com a realidade hegemônica imposta, entender se o ensino remoto é mais uma manobra do desgoverno atual e, pior, enfrentar o medo de que não se pretende voltar ao ensino presencial, quando muito, ainda enfrentarão a manutenção de um ensino híbrido. Além disso, os professores ainda estão diante da necessidade de ressignificar seus vínculos em face à pandemia, com seus alunos, colegas e com a própria relação pedagógica, afinal, o isolamento social causado pela pandemia por Covid-19, não resulta apenas em adaptações repentinas na docência universitária, mas acarreta mudanças em todos os aspectos da vida social (REGUEIRO et al., 2020).

Para além dos aspectos citados, Cunha (2020) mostra outras situações relacionadas à docência universitária, da universidade pública, que podem ser relacionadas a realidade do ensino remoto emergencial: a) a dimensão pedagógica; b) a relação com os estudantes; c) a gestão acadêmica, e d) os próprios docentes. $\mathrm{Na}$ dimensão pedagógica, se reconfigura a base epistemológica do conhecimento, do ensino e da pesquisa, modificando a relação teoria e prática, alterando a essência a docência, logo, os processos de ensinar e aprender, (MAGALHÃES; ARAUJO; ARGÜELLO, 2020; MAGALHÃES; FORTUNATO; MENA, 2020). A dimensão relacional no ensino remoto é deslocada para as casas e para o mundo, o que exige mais autonomia e protagonismo, além de ampliar as necessidades de novas aprendizagens interculturais (no sentido da interconectividade integral). Requer, inclusive, a revisão da dimensão afetiva, aspecto essencial em sala de aula. Por último, a dimensão da gestão acadêmica é aquela que reivindica lidar com as alterações curriculares (isso também envolve pensar sobre o paradigma educacional), o rever e reestruturar os espaços físicos e equipamentos para o ensino remoto, identificar as condições de acesso e aprendizagem dos estudantes (às vezes até a apoiar a compra de computadores e acesso às redes de internet), e aprender a ampliar a relação intercultural que se estabelece no processo (o ensino remoto não tem fronteiras e aproxima as culturas e comunidades). Por certo, todos os aspectos debatidos por Cunha (2020) colocam novas incertezas aos professores, todos os aspectos citados influem diretamente na docência, logo no processo formativo.

Soma-se as preocupações dos professores da universidade pública, na particularidade do curso de Pedagogia/Faculdade de educação/Universidade Federal de Goiás, a modificação das 


\section{Dialogia}

MAGALHÃES, Solange Martins Oliveira; SILVA, Simei Araújo; PAULA Leandro Silva de. Formação docente e interdisciplinaridade em tempos de pandemia Covid-19

ações docentes, e o como lidar com o novo formato das aulas remotas, e a imposição de uma formação teórica e epistemológica que resulte no "recuo da teoria", como bem descreveu Moraes (2001). Nesse sentido, os professores formadores, sobretudo das universidades públicas, mostramse comprometidos com a manutenção das aulas de forma remota, pelo menos a grande maioria, mas procuram manter o diálogo sobre os desafios impostos à docência universitária (MAGALHÃES; FORTUNATO; MENA, 2020).

Tentando enfrentar alguns dos desafios expostos, a proposta interdisciplinar e interativa parece filiar-se a uma docência crítica e emancipadora, como defendeu Fazenda (1998). Essa ideia norteou a proposição da atividade apresentada, bem como a organização de reflexões preliminares a respeito ensino remoto emergencial, sempre com foco de uma docência universitária sustentada como um dos princípios fundantes da universidade pública² (DIAS SOBRINHO, 2009), cabendo a ela ser definidora de valores que promovam a integralidade das formações, ou seja, manter a especificidade da formação integral - bildung (SOUZA, 2014; SOUZA; MAGALHÃES, 2017).

A aula interdisciplinar em tempos de pandemia: a visão dos estudantes de pedagogia/FE/UFG

Ao se entender que a docência universitária é a expressão dos princípios fundantes da universidade pública, cabe à ela ser responsável por valores que promovam a integralidade da formação no seu aspecto social, humano, ético e político, para que os estudantes sejam ativos e transformadores de nossa sociedade. Os princípios da formação citada são pautados numa educação que busca alterar a percepção dos sujeitos sobre o mundo, bem como assume o papel do conhecimento (suas várias formas), da ciência, seus valores, ideias, imagens, linguagens e representações, como mediadores da consciência (VIGOTSKI, 1999).

$\mathrm{Na}$ conjuntura atual do ensino remoto emergencial, mantemos o foco na docência como expressão de alternativas interdisciplinares que fortaleçam "um processo de aprender interessante e significativo, que proporcione uma efetiva formação profissional, condizente com as novas exigências" (MASETTO; GAETA, 2013, p. 115). Nesse sentido, a experiência relatada, e a posterior análise realizada a partir da avaliação de estudantes, nos aponta novas formas de superar uma perspectiva técnica e pragmática na formação de professores, além de expressar questões significativas e inquietantes, que foram postas aos discentes do primeiro período do curso de Pedagogia.

\footnotetext{
${ }^{2}$ Conforme Dias Sobrinho (2009, p. 55), no artigo 207 da Constituição Federal de 1988 (BRASIL, 1988), há a determinação da indi ssociabilidade entre ensino, pesquisa e extensão, como funções obrigatórias para a universidade pública. Isso também define o lugar da docência no ensino superior público.
} 
As atividades interdisciplinares foram desenvolvidas em quatro aulas (16h), articulando a participação de todos os estudantes do primeiro ano, com a explanação da temática "A representação da infância nas sociedades pré-modernas". As principais questões norteadoras que conduziram as aulas interdisciplinares e interativas foram: a) indagação da existência do sentimento de infância na Antiguidade e no Medievo; b) influência das transformações históricas, culturais e educacionais na construção das concepções de infância; c) diferenças entre os conceitos de criança e infância ao longo da história. O pressuposto deste trabalho foi a importância do diálogo entre diferentes áreas, compreendendo que o passado precisa ser investigado a partir das dúvidas do presente, o que nos direcionou à proposta interdisciplinar e colaborativa.

A atividade interdisciplinar articulou duas disciplinas: "Sociedade Cultura e Infância" e "História da Educação". A temática foi compartilhada entre os professores que a abordaram sob o prisma de suas diferentes áreas do conhecimento - História, Pedagogia, Psicologia. Os encontros síncronos foram realizados na plataforma Google Meet, quando o conteúdo era apresentado e debatido por todos. Após a realização de cada aula, foram aplicados questionários semiabertos para que as turmas avaliassem as atividades em amplo aspecto. Foram obtidas 141 respostas referentes aos estudantes que assistiram as aulas que serão considerados um universo fechado para a nossa investigação. Inicialmente, o intuito da aplicação dos formulários foi o de obter informações acerca de diferentes aspectos das aulas interdisciplinares no planejamento do "ERE", no curso de formação de professores.

Ao analisarmos as respostas, observamos que o questionário se tornara um instrumento de aprendizagem e fonte rica de informações que nos ajudaram a refletir sobre o nosso trabalho coletivo, durante o período de pandemia. A riqueza de informação sustentou a aprovação do grupo frente a atividade interdisciplinar, bem como em relação à adoção dessa iniciativa. Houve boa receptividade do tema proposto para as aulas e com relação ao tema - "a representação da infância nas sociedades pré-modernas" - identificamos interesse por $96 \%$ dos discentes. As considerações e os relatos dos estudantes destacaram elogios à iniciativa interdisciplinar adotada pelos docentes e o desejo de muitos discentes de que as aulas interdisciplinares tivessem continuidade ou que fossem criadas propostas análogas.

Analisando os depoimentos contidos nos questionários foi possível notar a compreensão dos alunos da importância de que as áreas do conhecimento se complementem de forma que os conteúdos disciplinares se apoiem no processo de aprendizagem. Representando alguns dos relatos, um(a) estudante de pedagogia afirmou: 
Aula produtiva e interativa. Vocês poderiam fazer mais vezes pois são matérias que caminham em vários momentos de "mãos dadas" o que acaba facilitando a compreensão de ambas (Relato número 16, questionário da turma da manhã, banco de dados criado por esta pesquisa).

Um fato que chama atenção nas declarações recebidas foi a constante afirmação da facilitação que aula interdisciplinar exerce no processo de aprendizagem.

[...] as aulas foram maravilhosas, adorei a ideia de juntar as matérias, achei as aulas super bem planejadas e eu compreendi muito melhor as matérias uma com o auxílio da outra [...]. (Relato número 34, questionário da turma da manhã, banco de dados criado por esta pesquisa).

Embora a metade dos estudantes tenham aprovado a ação docente, expressou-se certa contradição: apesar de ampla aprovação da iniciativa adotada, durante o período de ensino remoto emergencial, uma parcela significativa dos alunos relatou cansaço diante de aulas ofertadas, nas plataformas virtuais, também reclamaram do excesso de conteúdo exposto em um pequeno período de atividade interdisciplinar.

Vejamos o como se manifesta um estudante do noturno:

Super válida essa forma de contextualização, enriquece mais o conteúdo, já que as matérias elas têm uma certa ligação, uma complementa a outra. Achei fantástica a aula. (Relato número 01, questionário da turma da noite, banco de dados criado por esta pesquisa).

Em relação aos conteúdos, as preleções referentes ao tema "as representações da infância na Antiguidade", abordaram diferentes aspectos socioculturais de distintos períodos históricos das civilizações grega e romana, assim como as concepções referentes à infância existentes na filosofia, na literatura, nos mitos e na legislação da época. Por sua vez, as apresentações que possuíam como recorte cronológico a Idade Média, também acompanharam o mesmo percurso, iniciando pela contextualização histórica do século $\mathrm{V}$ até o XV e aprofundando na discussão relacionada à concepção de infância no cristianismo, na análise dos trajes e da presença das crianças na sociedade medieval; nos aspectos legais da época; nas instituições acolhedoras de infantes abandonados e em algumas concepções sobre a infância no Oriente. Sobre a amplitude dos conteúdos trabalhados nos encontros, um(a) aluno(a) do noturno afirmou:

[...] achei a aula muito boa, contudo, achei que tinha muito conteúdo para ser debatido em um tempo pequeno (...) grande quantidade de informações, que acaba não sendo muito proveitosa deste conteúdo. (Relato número 18 , questionário da turma da noite, banco de dados criado por esta pesquisa).

Vale destacar que cada aula ministrada teve como duração entre duas horas e duas horas e meia. Diante dos dados levantados, indaga-se se seria o conteúdo realmente excessivo, para ser 
trabalhado em um curto espaço de tempo, ou se o formato remoto das aulas intensificou o cansaço dos discentes? Apesar das críticas já identificadas, os depoimentos também sustentaram que as aulas interdisciplinares fossem ofertadas na modalidade presencial. Conforme pode-se contatar nos relatos a seguir:

[...] a carga de conteúdo por aula ficou um tanto pesada, muitas coisas de uma vez, difícil absolvição (absorção). Mas a ideia é muito boa! Espero que isso aconteça também quando retornarmos ao ensino presencial." (Relato número 21, questionário da turma da noite, banco de dados criado por esta pesquisa).

Após refletirmos sobre a atividade, por intermédio das perguntas fechadas do questionário, constatamos também que a experiência da aula interdisciplinar no formato remoto acabou gerando conflitos e contradições entre os estudantes. A carga horária foi significativamente criticada (3\%) e elogiada (97\%), e apesar do retorno positivo, as críticas se tornaram mais evidentes quando os futuros pedagogos descreveram suas opiniões no espaço reservado para a escrita de sugestões e/ou de avaliação geral dos encontros. Entre elogios, sobressaíram algumas sugestões: a) a possibilidade da realização de outro encontro destinado apenas para esclarecer as dúvidas dos alunos; b) a sugestão de que os docentes deveriam apresentar o conteúdo de forma mais objetiva e mais devagar; c) e a criação de uma dinâmica que possibilitasse a maior participação dos alunos.

De uma forma em geral, a aplicação do questionário e a possibilidade de os discentes registrarem suas considerações a respeito do processo de ensino e aprendizagem, exerceu um caráter formativo e transformador. Ou seja, o papel formativo possibilitou que os alunos criassem estratégias educativas para futuras aulas interdisciplinares na modalidade remota. Além do seu caráter pedagógico/transformador, que possibilitou compreender as apropriações que os alunos fizeram das aulas. Isso tornou-se visível na fala de alguns aprendizes que relataram que o estudo da história da infância possibilitou a melhor compreensão deles quanto ao papel da criança na sociedade contemporânea. Ver depoimento a seguir:

\footnotetext{
Acho muito importante retratar a história da infância e todo seu desenvolvimento. Para entendermos seu papel sociocultural nos dias de hoje devemos primeiro ver o seu impacto no passado, e as aulas interdisciplinares têm nos ajudado a compreender esses impactos e mudanças que fizeram da infância o que ela é hoje. (Relato número 5, questionário da turma da noite, banco de dados criado por esta pesquisa).
}

Freitas Neto (2005) afirmou que os alunos precisam se perceber como um ser social, ou seja, alguém que vive determinada época e que pertence a um determinado grupo. Uma das propostas ao se trabalhar a temática "história da infância" no curso de Pedagogia foi justamente a desenvolver nos discentes o olhar de estranhamento e o de identificação em relação aos sujeitos que viveram em diferentes períodos históricos. O que também reafirma nosso pressuposto teórico 
que sustenta o sujeito como sujeito social, histórico, capaz de articular mediações que participam da construção de sua consciência. Ao mesmo tempo, volta-se a sustentar a docência universitária como influenciadora da vida dos estudantes (MAGALHÃES; MOURA, 2020), como mediação pedagógica que promove, participa do processo de aquisição da consciência, a qual erige como possibilidade dinâmica de aprendizagem, sustentando a premissa de Vigotski (1999) que ressaltou o processo de aprendizagem, como fundamental no processo de desenvolvimento do sujeito social.

Por fim, identificamos que o desempenho dos docentes foi profícuo. Em relação ao desempenho dos professores diante das plataformas virtuais de aprendizagem, declara um(a) discente:

Nas aulas remotas (...) os professores nos deixaram bem tranquilos, pois sempre nas aulas síncronas tiram nossas dúvidas. (Relato número 18, questionário da turma da manhã, banco de dados criado por esta pesquisa).

Asseveramos que muitos alunos aproveitaram a existência de uma questão aberta no formulário para registrar suas impressões, reclamações, problemas e desafios enfrentados pelo ensino remoto durante a Pandemia do Covid-19 em 2020. Os estudantes também relataram muitas dificuldades com o ensino virtual: a) oscilação no acesso à internet durante o horário das aulas; b) solicitaram que os professores reduzissem a quantidade de atividades assíncronas em suas aulas (vale destacar que as aulas interdisciplinares apresentadas por este artigo previram apenas encontros síncronos, ou seja, os alunos aproveitaram a oportunidade para se expressar a respeito de questões que avançavam para além da atividade proposta); c) impossibilidade de frequentar as aulas interdisciplinares em determinados dias da semana, uma vez que alguns discentes não estavam matriculados nas duas disciplinas ao mesmo tempo.

Nem todos os alunos que pegam essa matéria são do $1^{\circ}$ período. Então não foi possível assistir as aulas na segunda-feira, pois o programado era na quarta-feira". (Relato número 14, questionário da turma da noite, banco de dados criado por esta pesquisa).

Diante dos dados expostos, constata-se os inúmeros benefícios de se trabalhar uma temática interdisciplinarmente, como uma forma de enfrentamento das dificuldades que devem ser enfrentadas no "ERE". Embora, seja necessário constantemente esclarecer aos estudantes que essa proposta visa romper com a perspectiva instrumental e pragmática associada a visão disciplinar que se propõe a contemplar o tema selecionado em sua completude, mas distanciada da interlocução e dialogia que a interdisciplinar exige. 
Algumas considerações sobre o ensino remoto emergencial: a perspectiva interdisciplinar e a docência na universidade pública em tempos de Pandemia Covid-19

As questões relacionadas ao impacto do ensino remoto emergencial na docência universitária, durante a quarentena do Covid-19, alteram os processos educativos, exigindo redimensionamento da função docente. As atividades interdisciplinares o comprometimento dos professores e alunos, e, nos limites e escopo das informações coletadas, o ensino remoto emergencial favoreceu o trabalho colaborativo, aliviou tensões iniciais, ajudou a superar o pragmatismo, atualmente imposto à docência universitária (ZANCHET; CUNHA; SOUZA, 2009). Nesse sentido, como afirmou Fazenda (2008), a prática interdisciplinar manteve os professores e estudantes em constante movimento de busca, do questionamento, da dúvida, da escuta do outro e do mundo, como formas de superação das dicotomias e contradições tão presentes no ensino remoto emergencial.

Quanto a questão da docência na universidade pública em sua articulação com a abordagem interdisciplinar, coloca os professores atentos às possibilidades de novas formas de docência: novos materiais, didáticas alternativas, saberes docentes, reações socioemocionais e emocionais manifestadas pelo grupo, aspectos importantes para a docência pensada para o ensino remoto emergencial. A atividade interdisciplinar favoreceu, portanto, a interação dos saberes disciplinares, apoiando professores e estudantes frente às novas exigências postas na formação docente.

Se o distanciamento social permanecer, se for assumida essa forma de ensino como "nova normalidade", ou até mesmo uma proposta hibrida, como bem coloca Araujo (2020, p. 8), provavelmente exigirá um sistemático esclarecimento do papel das atividades interdisciplinares no ensino remoto, elas poderão ajudar a superar problemas relacionados a fragmentação do ensino em sua versão remoto. Ao final, o tempo da pandemia amplia as experiências, a autonomia e, como afirmou Freire (1999), o respeito, dialogia, criatividade, criticidade, o que exige que o professor formador se reinvente, somente assim, a docência poderá se libertar da proposta disciplinar tradicional e passar a valorizar as atitudes de cooperação entre as disciplinas, não só no ensino remoto, mas sobretudo, no ensino presencial.

Por certo, as informações coletadas após a ação interdisciplinar, ainda não revelam tudo o que foi alcançado, embora a própria concepção de interdisciplinar impõe saber esperar o tempo das mudanças, elas ocorrerão, mas por agora, devemos acompanhar os acontecimentos, sempre com posicionamento crítico, pois resta-nos ficar atentos se os rumos assumidos são o que desejamos para a formação docente. Isso também envolve, como argumenta Souza Santos (2020), a forma como vamos lidar com a expressão da pedagogia do vírus, daremos conta de "empreender 


\section{Dialogia}

MAGALHÃES, Solange Martins Oliveira; SILVA, Simei Araújo; PAULA Leandro Silva de. Formação docente e interdisciplinaridade em tempos de pandemia Covid-19

esforços para compreendê-la para além de seus efeitos nocivos, assumindo-a como "uma janela de oportunidade para começar a mudar as coisas", ou ficaremos inertes frente aos acontecimentos? A docência universitária, na universidade pública, faz parte desse processo!

\section{Referências}

ARAUJO, Sonia Marcela. El desarrollo del curriculum universitario en tiempos de COVID19: oportunidad y contrariedad. Trayectorias Universitarias, v. 6, n. 10, p. 027, 20 ago. 2020. Disponível em: http://sedici.unlp.edu.ar/bitstream/handle/10915/104295/Documento_completo.pdfPDFA.pd?sequence=1\&isAllowed=y Acesso: 01/07/2021.

CUNHA, Maria Isabel da. Tensões do futuro: denunciar e enunciar em Educação. In: I Seminário Virtual da UESB, 2020. Disponível em: https://www.youtube.com/watch?v=A0_biq2AZrs. Acesso em: 01/07/2021.

DIAS SOBRINHO, José. Professor Universitário: contextos, problemas e oportunidades. In: CUNHA, Maria Isabel da et al. (Orgs.). Docência universitária: profissionalizạção e práticas educativas. Feira de Santana: UEFS Editora, 2009. p. 15-31.

FAZENDA, Ivani Catarina Arantes (Org.). Didática e interdisciplinaridade. Campinas, SP: Papirus, 1998.

FAZENDA, Ivani Catarina Arantes (Org.). Interdisciplinaridade: teoria, história e pesquisa. Campinas, SP: Papirus, 2008, $15^{\mathrm{a}}$ Edição.

FAZENDA, Ivani Catarina Arantes (Org.). O que é interdisciplinaridade? -2 ed. São Paulo: Cortez, 2013.

FAZENDA, Ivani Catarina Arantes (Org.). Práticas interdisciplinares na escola. 12 ed. São Paulo: Cortez, 2011a.

FAZENDA, Ivani Catarina Arantes (Org.). Integração e interdisciplinaridade no ensino brasileiro: efetividade ou ideologia. São Paulo: Loyola. 2011b.

FAZENDA, Ivani Catarina Arantes (Org.); GODOY, Herminia Prado. (coordenadora técnica). Interdisciplinaridade: pensar, pesquisar, intervir. São Paulo: Cortez, 2014.

FREIRE, Paulo. Pedagogia da autonomia. São Paulo: Editora Paz e Terra, 1999.

FREITAS NETO, José Alves de. A transversalidade e a renovação do ensino de história. In: KARNAL, Leandro (Org.). História na sala de aula: conceitos, práticas e propostas. São Paulo: Contexto, 2005.

MAGALHÃES, Solange Martins Oliveira; MOURA, Sílvia Adriane Tavares de. Epistemological aspects of rural education as result of social movements militancy. Brazilian Journal of Development, vol. 6, n. 9, 2020. Disponível em:

https://www.brazilianjournals.com/index.php/BRJD/article/view/17015/14232 Acesso em: 01/07/2021. 
MAGALHÃES, Solange Martins Oliveira; ARAUJO, Sonia; ARGÜELLO, Susana Beatriz. Agudización ultra neoliberal, educación y formación docente en Brasil y Argentina. Revista InterAção. Faculdade de Educação. Dossiê Neoliberalismo e educação: a escolarização pública e democrática sob risco. Volume 45, Número 1, jan/abr., 2020. Disponível em: https://www.revistas.ufg.br/interacao/article/view/62687/34789 Acesso em: 01/07/2021.

MAGALHÃES, Solange Martins Oliveira. Representações de crianças e sua educação: Presença e influência no processo formativo de professores. Revista Teias. v. 21. Ago. Edição Especial. ISSN 1518-5370 [impresso] • 1982-0305 [eletrônico]. DOI: 10.12957/teias, 2020. Disponível em: https://www.e-publicacoes.uerj.br/index.php/revistateias/article/view/46716 Acesso: 01/07/2021.

MAGALHÃES, Solange Martins Oliveira; FORTUNATO, Ivan; MENA, Juanjo. La universidad como resistencia: en busca de una epistemología de la práxis. Rev. HISTEDBR On-line. Campinas, SP v.20 1-14 e 020001, 2020. Disponível em:

https://periodicos.sbu.unicamp.br/ojs/index.php/histedbr/article/view/8655480 Aceso: 01/07/2021.

MARX, Karl; ENGELS, Friedrich. A Ideologia Alemã. São Paulo: Centauro, 2002.

MASETTO, Marcos T.; GAETA, Cecília. Docência com profissionalidade no Ensino Superior. In: Brazilian Geographical Journal: Geoscienses and Humanities Research Medium, Ituiutaba, v. 4, Special Issue 1, p. 299-310, jul./dez. 2013. Disponível em:

http://www.seer.ufu.br/index.php/braziliangeojournal/article/view/23445 Acesso: 01/07/2021.

REGUEIRO, Eloisa Maria Gatti.; VASCONCELOS, Elaine Cristine Lemes Mateus de; GONÇALVES, Adriana da Costa.; FIGUEIREDO; Maria Marisa Leonardi; VASCONCELOS, Everaldo Encide de; BELUZZO, Simone de Souza. Ensino mediado por tecnologias no curso de Fisioterapia do Centro Universitário Barão de Mauá durante o período de pandemia da Covid-19. Revista Interdisciplinar de Saúde e Educaşão, Ribeirão Preto, v. 1, n. 1, 2020. Disponível em: https://periodicos.baraodemaua.br/index.php/cse/article/view/36 Acesso: 01/07/2021.

SOUZA SANTOS, Boaventura. El virus es un pedagogo que nos intenta decir algo. El problema es saber si vamos a escucharlo. Entrevista realizada por $M^{a}$ Angeles Fernándezy J. Marcos. Ethic. Recuperado de: https://ethic.es/entrevis-tas/boaventura-de-sousa-santos-coronavirus/. Fecha de consulta: 12-08-2020. Disponível em: https:// ethic.es/entrevistas/boaventura-de-sousasantos-coronavirus/ Acesso: 01/07/2021.

SOUZA, Ruth Catarina Cerqueira Ribeiro de. Qualidades epistemológicas e sociais na formação, profissionalização e prática dos professores. In: SOUZA, Ruth Catarina Cerqueira Ribeiro de.; MAGALHÃES, Solange Martins de Oliveira. Poiésis e Práxis II. Formação, profissionalização, práticas pedagógicas. Goiânia: Kelps, 2014.

SOUZA, Ruth Catarina Cerqueira Ribeiro de.; MAGALHÃES, Solange Martins de Oliveira. Epistemologia da práxis e a produção do conhecimento. Revista de Educação Pública, v. 27, n. 64, p. 17-40, 2017. Disponível em:

https://periodicoscientificos.ufmt.br/ojs/index.php/educacaopublica/article/view/1702

Acesso: 01/07/2021. 


\section{Dialogia}

MAGALHÃES, Solange Martins Oliveira; SILVA, Simei Araújo; PAULA Leandro Silva de. Formação docente e interdisciplinaridade em tempos de pandemia Covid-19

VIGOTSKI, Lev Semionovitch. A formação social da mente. São Paulo: Martins Fontes, 1999.

ZANCHET, Beatriz Maria B. Atrib; CUNHA, Maria Isabel; SOUSA, Helena Mascarenhas. A Pós-Graduação como lugar de formação e de aprendizagens de professores universitários. Educação, Sociedade \& Culturas. Porto, v. 28, p. 93-105, 2009. Disponível em: https://www.fpce.up.pt/ciie/revistaesc/ESC28/28_beatriz.pdf Acesso: 01/07/2021. 